Brit. F. industr. Med., 1968, 25, 315.

\title{
Uptake of Mercury by the Brain
}

\author{
L. MAGOS \\ From the Toxicology Research Unit, Medical Research Council Laboratories, Woodmansterne Road, \\ Carshalton, Surrey
}

A technique has been developed for injecting metallic mercury intravenously in aqueous solution. Thirty seconds after intravenous injection of rats with $0.1 \mu \mathrm{g}$. metallic mercury labelled with ${ }^{203} \mathrm{Hg}$ nearly $20 \%$ of the dose had been exhaled and the concentration in the brain was nearly as high as in the blood. After injection of mercuric ion little of the dose was exhaled, and brain uptake was much less. Oxidation of mercury in the blood was, therefore, not instantaneous, and the rapid transport of the unconverted metallic mercury to the brain and its subsequent rapid diffusion from the blood was responsible for the high level of mercury in the brain after exposure to mercury vapour. The technique might be useful for the study of the passage of highly diffusible vapours through the respiratory membranes.

After the inhalation of metallic mercury vapour, a higher fraction of the mercury in the body is found in the brain than after the parenteral injection of a mercuric salt (Berlin, Jerksell, and Ubisch, 1966). This observation might explain why those exposed to mercury vapour show evidence of toxic effects in the brain rather than evidence of kidney damage, while the converse is true after the uptake of a mercuric salt.

This paper is concerned with the question whether mercury introduced into the blood stream as elemental mercury is transported as such by blood to the brain, or whether it is oxidized to mercuric ions first. More evidence is given that it is transported as elemental mercury, as already suggested (Magos, 1967b), and the implications of this for brain uptake are discussed.

\section{Materials and Methods}

Animals Female albino Wistar rats (Porton strain) weighing 200-220 g. were used. The left jugular vein was cannulated with polythene tubing (internal diameter $0.4 \mathrm{~mm}$.) under ether anaesthesia (Ginsburg and Heller. 1953) at least four days before the experiment. Solutions containing the mercury were injected into the jugular cannula. The mercury appearing in the exhaled air was collected by placing the head of the animal in a small funnel connected with a hopcalite absorber (Magos, 1966) through which air was aspirated at a rate of I.5 1./minute. All the rats except two were decapitated at set times after injection. Blood, brain, kidneys, and, in some cases, the lungs and the heart were taken. The

Received for publication April I I, 1968. organs were washed with saline. Two animals were anaesthetized with $70 \mathrm{mg}$. $/ \mathrm{kg}$. diethylbarbituric acid ${ }^{1}$, and $30 \mathrm{sec}$. after the injection blood was collected from the chest cavity.

Injection Technique and Solutions The metallic mercury was injected by a system employing two syringes (Fig. I). Syringe I contained a solution of stannous ions which during the injection procedure reduced the mercuric ions injected by a $0.25 \mathrm{ml}$. tuberculin syringe (syringe 2 ). The mercury from syringe

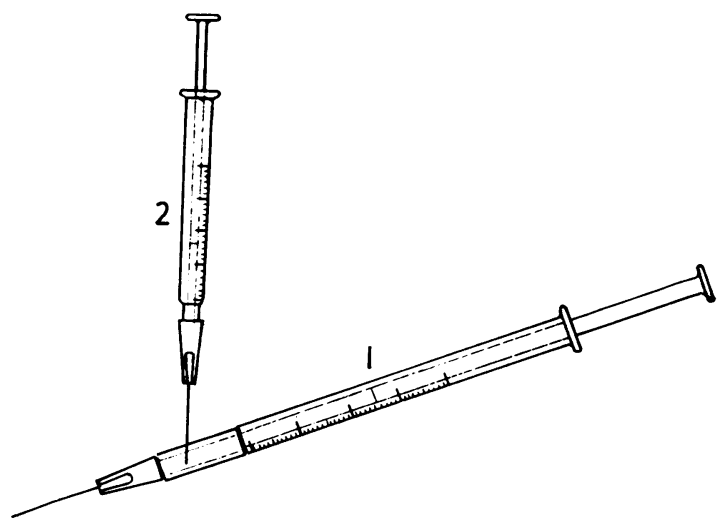

FIG. I. System of two syringes used for injection of metallic mercury in the metallic form. Syringe I contained the $\mathrm{SnCl}_{2}$ which reduced the mercuric ions injected from syringe 2 .

${ }^{1}$ Supplied by CIBA Laboratories Ltd, Horsham, Sussex. 
2 was injected into a transparent vinyl tubing, $20 \mathrm{~mm}$. long, which connected the nipple of a needle (size I7) and the nipple of a $\mathrm{I} \cdot 0 \mathrm{ml}$. tuberculin syringe (syringe I). The nipple of the needle was formed by fixing a semi-rigid polythene tube, $15 \mathrm{~mm}$. long (outer diameter $4.25 \mathrm{~mm}$., bore $0.8 \mathrm{~mm}$.), into the plastic mount of the needle.

The solution of metallic mercury for injection was obtained as follows. Stannous chloride (30-40 mg., $\mathrm{SnCl}_{2} \cdot 2 \mathrm{H}_{2} \mathrm{O}$ ) was added to a test tube containing $5 \mathrm{ml}$. isotonic phosphate buffer ( 100 parts of O.I $\mathrm{M} \mathrm{NaHPO}_{4}+$ 2 parts of $\mathbf{I} \cdot 0 \mathrm{~N} \mathrm{HCl}$ ) and was shaken and allowed to stand for a few minutes until a clear supernatant, containing stannous ions, appeared. Syringe I was filled up to the 0.1 mark from the supernatant and the needle was connected with the cannula. Syringe 2 contained $0.1 \pm 0.02 \mu \mathrm{g} .{ }^{203} \mathrm{Hg}, 0.4 \mu \mathrm{C}$, as mercuric acetate ${ }^{2}$ in $0.1 \mathrm{ml}$. O.I N $\mathrm{HNO}_{3}$. Syringe I was emptied steadily and during the first half of the emptying period syringe 2 was discharged so that the contents of both syringes were mixed and gave an injection of metallic mercury swept in by the last half of the content of syringe $I$. In control experiments syringe I was filled with saline $(0.9 \% \mathrm{NaCl}$ in water), and in syringe 2 saline was substituted for $0.1 \mathrm{~N} \mathrm{HNO}_{3}$ so that the injection was of mercuric chloride.

Validation of the Method The procedure was shown to give metallic mercury in dummy experiments. The same set-up of syringes was emptied through a cannula into a stoppered test tube containing $2 \mathrm{ml}$. isotonic saline through which air was drawn at $\mathbf{I} \cdot 0 \mathrm{l}$./min. and then passed through hopcalite. Reduction was stopped at $30 \mathrm{sec}$. by injecting I ml. $0.05 \mathrm{M}$ potassium permanganate in $5 \%$ sulphuric acid into the test tube. The hopcalite contained $84 \pm 5.5 \%$ ( \pm S.D.) of the mercury injected. When $\mathrm{HgCl}_{2}$ was injected only $3 \cdot 6 \pm 1 \cdot 2 \%$ ( \pm S.D.) of the mercury appeared in the hopcalite.

Determination of ${ }^{203} \mathbf{H g}$ The mercury content (measured as ${ }^{203} \mathrm{Hg}$ ) of the organs, blood ( $2 \mathrm{ml}$. samples) or hopcalite was estimated by an automatic scintillation counter (Model 450A, Packard Instrument Co., La Grange, Ill., U.S.A.) having a counting efficiency of $40 \%$. Mercury contents were expressed in percentages of the total amount of mercury injected. Before each injection the same amount of mercury was added from syringe 2 to $2.0 \mathrm{ml}$. potassium permanganate-sulphuric acid solution, and this was taken as the dose given. In some experiments the exhalation of mercury was followed by immersing the hopcalite absorber into the well of a scintillation detector (N664B) with a scaler ${ }^{3}$ (N6IOA) connected with a recorder. Metallic mercury in blood was separated by the liquid phase nitrogen phase separation technique followed by absorption from the nitrogen phase on hopcalite already described (Magos, 1967b).

${ }^{2}$ Radiochemical Centre, Amersham, Bucks.

${ }^{3}$ Ekco Electronics Ltd.

${ }^{4}$ Honeywell Controls, Ltd.

\section{Results}

After injection of metallic mercury $16 \cdot 7 \pm \mathrm{I} \cdot 08 \%$ ( \pm S.E.M., $\mathbf{n}=7$ ) of the dose was excreted as metallic mercury in the exhaled air. In the separate experiments shown in Table I, $18.6 \%$ was exhaled. Exhalation of mercury started immediately after injection and lasted about I5 sec. (Fig. 2). After injection of mercuric chloride much less mercury was exhaled, and $30 \mathrm{sec}$. after the injection the lungs, brain, and heart contained less mercury than those from animals injected with metallic mercury (Table I). Furthermore, the blood of the animals given metallic mercury retained only $6 \%$ of the injected dose in contrast to the $45 \%$ remaining in the blood of those given mercuric chloride. When metallic mercury was injected into anaesthetized animals, less mercury was exhaled and more was retained by the lungs than in unanaesthetized rats, but the total amounts (lungs + exhaled air) were very similar (Table I), indicating that the difference could be attributed to a reduced ventilation rate. The disappearance from blood was nearly as fast as in the unanaesthetized rats and very much faster than in rats given mercuric chloride. The presence of metallic mercury in the blood of these rats $30 \mathrm{sec}$. after injection was demonstrated, $3.7 \%$ of the mercury in the blood being in the metallic form.

The percentages of mercury found in the tissues changed very little from 0.5 to $5 \mathrm{~min}$. after the injection of metallic mercury, and the ratio of concentrations, brain : blood, was high; whereas

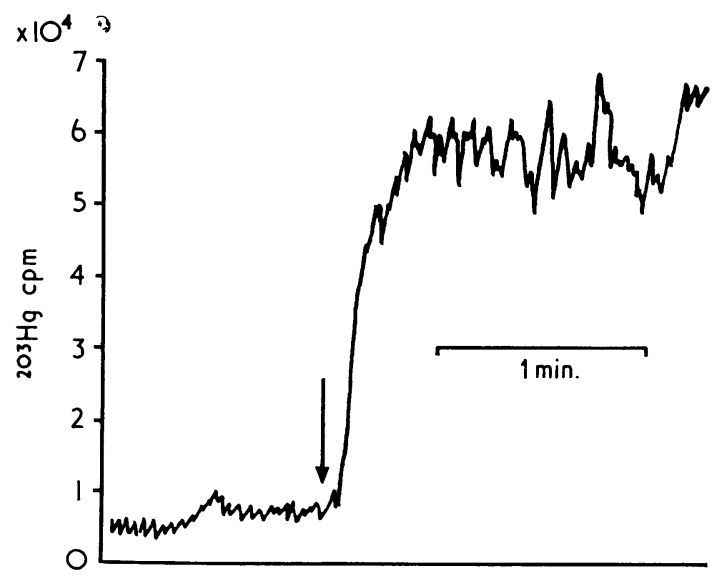

FIG. 2. Appearance of ${ }^{203} \mathrm{Hg}$ in exhaled air after intravenous injection of metallic mercury. Mercury was injected at the arrow. As ${ }^{203} \mathrm{Hg}$ was expired the count rate in the hopcalite rose rapidly from its background level to a new high level, which became steady, except for statistical fluctuations, when excretion ceased. 
TABLE I

Distribution of Mercury in Rats 30 Sec. AfTer InjeCtion OF O. I $\mu$ g. Mercury

\begin{tabular}{|c|c|c|c|c|c|c|c|c|}
\hline \multirow{2}{*}{$\begin{array}{c}\mathrm{Hg} \text { injected } \\
\text { as }\end{array}$} & \multirow[b]{2}{*}{ Anaesthesia } & \multirow{2}{*}{$\begin{array}{c}\text { No. of } \\
\text { Experiments }\end{array}$} & \multicolumn{6}{|c|}{ Mercury as $\%$ of Dose in } \\
\hline & & & $\begin{array}{c}\text { Exhaled } \\
\text { Air }\end{array}$ & Lung & Heart & Kidneys & Brain & Blood \\
\hline $\begin{array}{l}\text { Metallic } \\
\text { Chloride } \\
\text { Metallic }\end{array}$ & $\frac{-}{+}$ & $\begin{array}{l}3 \\
3 \\
2\end{array}$ & $\begin{array}{r}18 \cdot 6 \\
1 \cdot 8 \\
3 \cdot 7\end{array}$ & $\begin{array}{r}8 \cdot 8 \\
2 \cdot 3 \\
16 \cdot 7\end{array}$ & $\begin{array}{l}1 \cdot 7 \\
1 \cdot 2 \\
-\end{array}$ & $\begin{array}{l}2 \cdot 3 \\
3 \cdot 5 \\
5 \cdot 8\end{array}$ & $\begin{array}{l}0.60 \\
0.34 \\
I \cdot 37\end{array}$ & $\begin{array}{r}5 \cdot 9 \\
44 \cdot 9 \\
7 \cdot 2\end{array}$ \\
\hline
\end{tabular}

TABLE II

Mercury Contents of Brain, Blood, and Kidneys and Brain: Blood Ratio after Injection of O I $\mu$ g. Mercury

\begin{tabular}{|c|c|c|c|c|c|c|}
\hline \multirow{2}{*}{$\begin{array}{c}\mathrm{Hg} \text { injected } \\
\text { as }\end{array}$} & \multirow{2}{*}{$\begin{array}{c}\text { Time after } \\
\text { Injection } \\
(\text { min. })\end{array}$} & \multirow{2}{*}{$\begin{array}{c}\text { No. of } \\
\text { Experiments }\end{array}$} & \multicolumn{3}{|c|}{ Mercury as $\%$ of Dose } & \multirow{2}{*}{$\begin{array}{c}\text { Brain:Blood } \\
\text { Ratio }\end{array}$} \\
\hline & & & per g. Brain & per ml. Blood & perg. Kidneys & \\
\hline Metallic & $\begin{array}{l}\frac{1}{2} \\
2 \\
5\end{array}$ & $\begin{array}{l}8 \\
7 \\
6\end{array}$ & $\begin{array}{c}0.330 \\
( \pm 0.017) \\
0.290 \\
( \pm 0.027) \\
0.298 \\
( \pm 0.059)\end{array}$ & $\begin{array}{c}0.48 \\
( \pm 0.038) \\
0.39 \\
( \pm 0.032) \\
0.37 \\
( \pm 0.036)\end{array}$ & $\begin{array}{r}1 \cdot 10 \\
( \pm 0.09) \\
1 \cdot 26 \\
( \pm 0.13) \\
1 \cdot 33 \\
( \pm 0.16)\end{array}$ & $\begin{array}{c}0.699 \\
( \pm 0.06 \mathrm{I}) \\
0.75 \mathrm{I} \\
( \pm 0.18 \mathrm{I}) \\
0.800 \\
( \pm 0.079)\end{array}$ \\
\hline Chloride & $\begin{array}{l}\frac{1}{2} \\
2 \\
5\end{array}$ & $\begin{array}{l}9 \\
5 \\
5\end{array}$ & $\begin{array}{c}0.213 \\
( \pm 0.016) \\
0.144 \\
( \pm 0.009) \\
0.118 \\
( \pm 0.010)\end{array}$ & $\begin{array}{c}3.68 \\
( \pm 0.33) \\
2.52 \\
( \pm 0.21) \\
2.33 \\
( \pm 0.05)\end{array}$ & $\begin{array}{c}1 \cdot 77 \\
( \pm 0.61) \\
2.99 \\
( \pm 0.32) \\
4.25 \\
( \pm 0.31)\end{array}$ & $\begin{array}{c}0.061 \\
( \pm 0.006) \\
0.059 \\
( \pm 0.006) \\
0.050 \\
( \pm 0.004)\end{array}$ \\
\hline
\end{tabular}

The numbers in parentheses are the standard errors.

after injection of mercuric chloride the percentages found in the blood and brain decreased and in the kidneys increased with time after injection, and the ratio brain : blood was only a tenth of that after metallic mercury (Table II).

\section{Discussion}

It has been previously shown by in vitro experiments that the conversion of elemental mercury to mercuric ion by blood was not instantaneous and seemed to be slow when compared with the single circulation time which is enough to carry the mercury from the lungs to the brain (Magos, 1967b). The present experiments showed that the same was true in vivo.

The most direct evidence was the appearance of mercury in the exhaled air. When metallic mercury was injected into the jugular cannula nearly $20 \%$ of the injected dose was exhaled (Table I), showing that a high proportion of the mercury had been transported in the metallic form from the cannula to the lungs. Concerning the localization of the transfer from the blood to the exhaled air, the high rate of exhalation indicates that the major part of the mercury exhaled left the blood through the alveolar membranes rather than through the lining of the physiological dead space. If the same part of the respiratory system participates in both the uptake and the clearance, these experiments favour the view of Kudsk (1965), who, in contrast to Teisinger and Fiserova-Bergerova (1965), suggested that mercury is absorbed through the alveoli and not through the upper part of the respiratory tract. In anaesthetized animals, due to reduction in the ventilation rate, exhalation was significantly less, but the amount of mercury retained by the lungs was much greater, the total amounts being similar.

After mercuric chloride injection very much less mercury was exhaled. However, some was-about $2 \%$ from the unanaesthetized rat. This is not surprising as in a solution of mercuric salt there is always some free mercury, i.e., mercuric, mercurous, and mercury are in equilibrium: $\mathbf{H g}+\mathrm{Hg}^{++} \rightleftharpoons$ $\mathrm{Hg}_{2}{ }^{++}$, so that if mercury is removed from solution it is replaced at a steady rate (Magos, $1966 ; 1967 a$ ). 
In vivo the existence of this equilibrium leads us to expect that some free mercury will always be present, in accordance with the finding that some mercury was exhaled. Any system which complexes mercuric ions should reduce the concentration of free mercury. Accordingly, Clarkson and Rothstein (1964) found that only $0.08 \%$ of the dose was exhaled within $5 \mathrm{hr}$. after injection of a mercuryglutathione complex, much less than in the present experiments. The presence of free mercury in blood after injection of mercuric salts suggests that brain takes up metallic mercury even in this case, but much more slowly because of the lower concentrations.

The analysis of the blood $30 \mathrm{sec}$. after the injection supplied more evidence that the mercury injected as metallic mercury reached the organs in a different form from that injected as mercuric chloride. In the first case, by $30 \mathrm{sec}$. the blood contained only $5.9 \%$ of the dose. Allowing that $20 \%$ was exhaled or in the lungs, and that there are $7.0 \mathrm{ml}$. blood $/ 100 \mathrm{~g}$. rat, it follows that the blood contained almost exactly the same concentration of mercury as the extravascular system as a whole. After mercuric chloride the blood contained $45 \%$ of the dose, about II times the concentration outside the blood stream. This corresponds to an enormous difference in the rate of uptake of mercury from the blood stream in the two cases. After $30 \mathrm{sec}$. the concentrations in the blood fell slowly in both cases (Table II) as expected, as in both cases the mercury was present in the same oxidized state by this time.

The brain:blood ratio of concentrations was about Io times higher $30 \mathrm{sec}$. after metallic mercury than after mercuric salt, and in the latter case the ratio decreased with time, indicating that a high proportion of the mercury measured in the brain was actually in the blood or was bound to the inner surface of the small blood vessels. The latter factor may well have played a part following the injection of mercuric chloride because correction of the brain concentrations for a blood content of $0.01 \mathrm{ml} . / \mathrm{g}$. (Lajtha, Furst, Gerstein, and Waelsch, 1957) did not eliminate the rapid decrease of the brain concentrations. After metallic mercury the ratio slightly increased with time, so the contribution of the vascular + blood mercury to the brain mercury should have been significant. It was, however, observed that the variance of mercury concentration in brain at $5 \mathrm{~min}$. was significantly greater ( $\mathrm{P}<0.01, \mathrm{~F}$ test) (Snedecor, 1946) than at $0.5 \mathrm{~min}$. (Table II). This may indicate that the rate of oxidation of metallic mercury in the brain varied from rat to rat.

After metallic mercury the concentration in the brain was nearly as high as in the animal as a whole, as found after the inhalation of mercury vapour (Magos, I967b). The rapidity of the uptake shows that most of the mercury was taken up during the first passage of blood through the brain after the injection. It is difficult to believe that during this short time the mercury is oxidized and again regenerated as metallic mercury, as was proposed by Berlin (I966).

The author wishes to thank Mr. R. Lock for technical assistance.

\section{REFERENCES}

Berlin, M. (1966). Recent progress in mercury toxicology research and its consequences for current mercury problems. XV int. Congr. occup. Hith., Vol. III, p. 107.

- Jerksell, L. G., and Ubisch, H. von (1966). Uptake and retention of mercury in the mouse brain. Arch. environm. Hlth, 12, 33-42.

Clarkson, T., and Rothstein, A. (1964). The excretion of volatile mercury by rats injected with mercuric salts. Hlth Phys., 10, II $15-1121$.

Ginsburg, M., and Heller, H. (1953). The antidiuretic assay of vasopressin by intravenous injection into unanaesthetized rats. F. Endocr., 9, 267-273.

Kudsk, F. N. (1965). Absorption of mercury vapour from the respiratory tract in man. Acta pharmacol. (Kbh.), 23, 250-262.

Lajtha, A., Furst, S., Gerstein, A., and Waelsch, H. (1957). Amino acid and protein metabolism of the brain-I. Turnover of free and protein bound lysine in brain and other organs. F. Neurochem, 1, 289-300.

Magos, L. (1966). Radiochemical determination of metallic mercury vapour in air. Brit. f. industr. Med., 23, 230-236.

- (1967a). The effect of halide ions on the $\mathrm{Hg} \rightleftharpoons{ }^{203} \mathrm{Hg}$ exchange reaction between air and aqueous solution. f. chem. Soc. $(A)$, pp. 545-546.

- (1967b). Mercury blood interaction and mercury uptake by the brain. Environm. Res., 1, 323-337.

Snedecor, G. W. (1946). Statistical Methods. p. 214. Iowa State College Press, Ames, Iowa.

Teisinger, J., and Fiserova-Bergerova, V. (1965). Pulmonary retention and excretion of mercury vapours in man. Industr. Med. Surg., 34, 580-584. 